\title{
Health financing and family planning in the context of universal health care: Connecting the discourse in Kenya
}

Gabrielle Appleford

Saumya RamaRao

Population Council

Follow this and additional works at: https://knowledgecommons.popcouncil.org/departments_sbsr-rh

Part of the Demography, Population, and Ecology Commons, Family, Life Course, and Society Commons, Health Policy Commons, and the International Public Health Commons How does access to this work benefit you? Let us know!

\section{Recommended Citation}

Appleford, Gabrielle and Saumya RamaRao. 2019. "Health financing and family planning in the context of universal health care: Connecting the discourse in Kenya," brief. New York: Population Council. 


\section{HEALTH FINANCING AND FAMILY PLANNING IN THE CONTEXT OF UNIVERSAL HEALTH CARE: CONNECTING THE DISCOURSE IN KENYA}

\section{INTRODUCTION}

Financing is a major challenge and concern for the future of family planning (FP) programs. As countries commit to increasing access to and quality of FP services and to universal health coverage (UHC), it is crucial that UHC schemes include FP and other reproductive health $(\mathrm{RH})$ services. Strategic purchasing of FP quality services from public and private - including for profit and not-for-profit - healthcare providers could accelerate progress toward UHC.

It is increasingly recognized that the FP2020 goals will not be met without adequate attention to quality; and that a sustained focus on quality of care requires financing at the policy and program levels. While the importance of financing is recognized in relation to quality, the 'how' of financing FP within the context of UHC is not well understood.

This brief targets the 'bridge' constituency that is coalescing between the health financing and FP communities of practice around a shared interest in making access to health services universal. With this brief, we aim to highlight experiences in Kenya, given that there is a body of experience with health financing reforms and UHC schemes and a relatively strong national FP program. The Kenya case study is instructive for other countries with decentralized and mixed health systems as they seek to integrate FP within their own UHC initiatives and health financing reforms.

\section{METHODOLOGY AND OUTLINE}

The Kenya brief is the companion to the technical brief entitled 'Health financing and family planning in the context of Universal Health Care: connecting the discourse.' It has drawn upon on selected published and grey literature on health financing, FP and $\mathrm{UHC}$ within in the Kenya context. The Kenya brief is presented using the $5 \mathrm{P}$ 'organizing framework' in (Table 1) overleaf.

\section{POLITIES - WHY TO PURCHASE}

The Government of Kenya (GoK) has expressed its political commitment to UHC and the provision of quality health care for all. This is articulated in the Constitution of Kenya (2010) and Kenya Vision 2030 long-term development goals. To enable Kenyans to realize their constitutional right to health, the GoK has prioritized universal access to primary health care $(\mathrm{PHC})$ with attention to maternal, newborn and child health $(\mathrm{MNCH})$ services. An $\mathrm{MNCH}$ focus does not make explicit the societal and economic benefits of FP nor is this politically championed. $\mathrm{MNCH}$ also competes with other priority interventions, such as non-communicable diseases (NCDs). PHC services, $\mathrm{MNCH}$ and FP inclusive, are challenged by gaps in coverage of essential health services and quality
FIGURE 1. Health facility in Bungoma County, Kenya

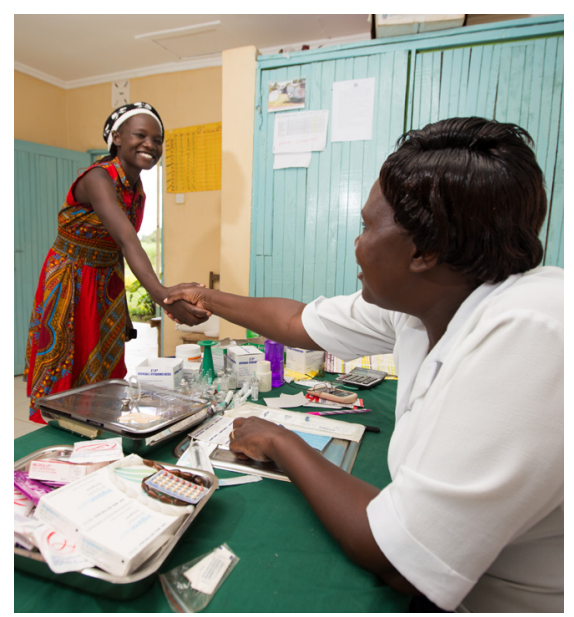

Photo Credit: Population Council 


\begin{tabular}{|c|c|c|}
\hline Purchasing domains & Purchasing elements & FP considerations \\
\hline $\begin{array}{l}\text { Polities: Why to purchase (rationale } \\
\text { and institutional arrangements) }\end{array}$ & $\begin{array}{ll} & \text { Political commitment } \\
\text { - } & \text { Institutional arrangements } \\
\text { - } & \text { Purchaser alignment (across } \\
& \text { mechanisms) } \\
\text { - } & \text { Monitoring and accountability } \\
\text { - } & \text { Performance management }\end{array}$ & $\begin{array}{ll}\text { - } & \text { Societal benefits (FP rights, } \\
\text { gender equality) } \\
\text { Economic benefits } \\
\text { (demographic dividend) } \\
\text { - } \\
\text { ability to realise rights for FP } \\
\text { - Stewardship and ownership (e.g. } \\
\text { government and donors, central } \\
\text { and decentralized) } \\
\text { Fragmentation and adequacy of } \\
\text { financing (horizontal and } \\
\text { vertical coherence) }\end{array}$ \\
\hline People: For whom to purchase & $\begin{array}{ll}\text { - } & \text { Defined target clientele } \\
\text { - } & \text { Clientele awareness } \\
& \text { Community and society } \\
& \text { engagement }\end{array}$ & $\begin{array}{l}\text { - Unmet need } \\
\text { - } \quad \text { mequity (e.g. poor women and } \\
\text { - Client continued use (through } \\
\text { method choice) } \\
\text { - Financial barriers/out-of-pocket } \\
\text { expenditure }\end{array}$ \\
\hline Package: What to purchase & $\begin{array}{l}\text { - } \quad \text { Defined benefit objectives } \\
\text { - } \quad \text { Defined benefit package }\end{array}$ & $\begin{array}{l}\text { - Broad method mix to improve } \\
\text { choice, enable switching, and } \\
\text { reduce discontinuation } \\
\text { - FP integration into RMNCAH } \\
\text { continuum/packages }\end{array}$ \\
\hline Provider: From whom to purchase & $\begin{array}{ll}\text { - } & \text { Contracting } \\
\text { - } & \text { Accreditation } \\
\text { Integration (of public and } \\
\text { private providers) }\end{array}$ & $\begin{array}{l}\text { - } \quad \text { Physical access/choice of outlet } \\
\text { - } \quad \text { Integration of the private sector } \\
\text { - } \quad \text { Client realization of FP rights }\end{array}$ \\
\hline Payment: How to purchase & $\begin{array}{l}\text { - } \quad \text { Payment rates } \\
\text { - } \quad \text { Payment methods } \\
\text { - } \quad \text { Provider autonomy } \\
\text { - } \quad \text { Quality assurance (data and } \\
\text { clinical) }\end{array}$ & $\begin{array}{l}\text { - Likelihood of being offered } \\
\text { choice of FP method (e.g. pro- } \\
\text { vider behaviour) } \\
\text { - } \quad \text { Efficiency and quality } \\
\text { - } \\
\text { Regulatory and public financial } \\
\text { management }\end{array}$ \\
\hline
\end{tabular}

of care, with high provider absence from health facilities, low adherence to clinical guidelines, and deficits in commodities and infrastructure (World Bank, 2013).

\section{Political commitment has not translated into adequate} domestic financing and is one reason for observed health system impediments. The GoK spends about US\$2.7 billion on health care annually, or approximately $\$ 55$ per capita, allocating about a third of the amount committed to under the Abuja Declaration; this proportion has been decreasing over time (GoK/MoH, 2016). About $63.3 \%$ of total health expenditure (THE) is funded publicly, including donor support and health insurance (11\% THE) while a further $36.7 \%$ is funded privately, predominately through out-of-pocket (OOP) expenditure at the point of service $(\mathrm{GoK} / \mathrm{MoH}, 2012)$. Donor and private sector contributions have declined over time and remain largely off-budget and issue-specific (GoK/MoH, 2012).

While the GoK is increasingly using the language of UHC, there is a lack of alignment of health financing mecha- nisms. A health financing strategy has been drafted but has yet to be endorsed $(\mathrm{GoK} / \mathrm{MoH}, 2012)$. Financing is further complicated by devolution, through which the 47 county governments control more than two thirds of health expenditure (GoK/MoH, 2015). The National Hospital Insurance Fund (NHIF), considered the main vehicle for UHC, covers about $20 \%$ of the population, mostly through mandatory enrollment of the formal sector. Efforts are in place to expand coverage, including the informal sector and indigent populations which should see this proportion increase. The more recent UHC pilot in four counties, which was intended to operate through the NHIF, has by-passed this scheme, and will see user fees removed writ large in the public sector. It is unclear what the implications of this move mean to the NHIF or UHC plans more broadly.

\section{Health care purchasing arrangements are largely pas-} sive and not performance-based. At present, the GoK has focused on input-based financing through pre-determined annual budgets allocated through the Ministry of Finance. 


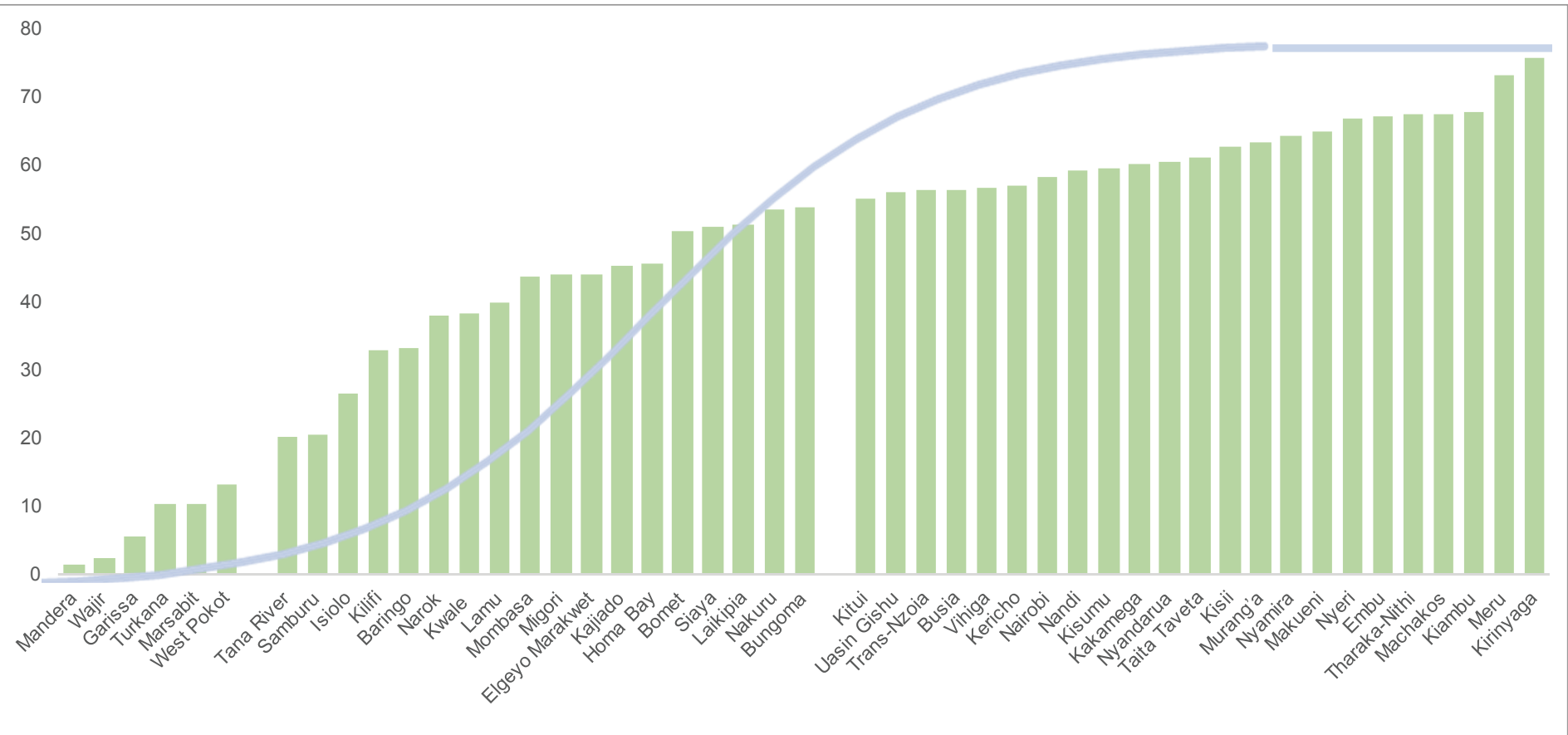

Source: Avenir Health/Track20

Output-based financing is also done, mainly through the NHIF. There is no definition of strategic purchasing provided for within $\mathrm{MoH}$ policy documents, however the NHIF refers to this as the "continuous search for the best ways to maximise health system performance by deciding which interventions should be purchased, how, and from whom' based on the Resilient and Responsive Health Systems (RESYST) definition (RESYST, 2014).

\section{PEOPLE: FOR WHOM TO PURCHASE}

There has been uneven progress in reaching women with FP services. While recent data indicate that Kenya has achieved its FP2020 goal of 58\% modern contraceptive use by married women, progress has been starkly uneven across the country: the modern contraceptive prevalence rate ( $\mathrm{mCPR}$ ) remains as low as $2 \%$ among married women in northeastern counties, compared to $76 \%$ in central counties - and the rate of contraceptive use among the poorest is half that of the rest of the population (GoK/KNBS, 2014). There is also very high unmet need within the 15-24-yearold cohort (48\%) and in rural areas where women tend to have sex earlier and use contraception later (IQVIA, 2018). This suggests that both supply- and demand-side barriers continue to limit access to FP, particularly for poor women, men, and adolescents.

It is unclear the contribution of financial barriers to access and equity constraints for the poor and other marginalised populations. There is a lack of comprehensive data to estimate OOP expenditure on $\mathrm{RH}$, including FP (Sidze et al, 2013). While FP services are intended to be free within the public health system, a study by Radovich et al (2017) indicated that only one-half of modern method users reported obtaining their method at no cost. Monitoring by PMA2020 also estimated that $73.5 \%$ of women paid for FP services, despite $60 \%$ of women receiving their service from a public service delivery point, where FP is supposed to be free at point of use. This suggests that FP OOP expenditure is ubiquitous in Kenya.

There is increasing emphasis on differentiating population segments so that FP subsidies can be targeted towards those who need it. This is in recognition of limitations with government domestic financing and over reliance on donor financing (FP2020 Kenya, 2018). Donor and government financing have largely focused on commodities, given predicted financing gaps in the commodity pipeline, which have been further complicated by devolution. In response, a total market approach (TMA) has been proposed in order to 'differentiate population segments according to ability to pay and identify which market players are best placed to reach each segment' (FP2020 Kenya).

This approach assumes an ability to segment the market based on willingness to pay and may not consider the intersectionality of gender with other social stratifiers. For example, women already incur more OOP costs for health than men and OOP expenditure may prevent more women than men from utilizing essential services (Witter et al, 2017). While the global evidence on user fees as a barrier to FP is inconclusive, poorer and/or younger populations appear more price sensitive than the average population (Korachais et al, 2016). In the Kenya context, given high 
FIGURE 3. NHIF benefit packages (national scheme)

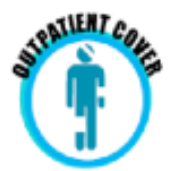

Outpatient Care
Consultation, lab services, investigations,
daycare procedures, physiotherapy

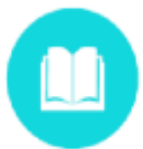

Imaging services

MRI, CT scans \& Ultra Sound

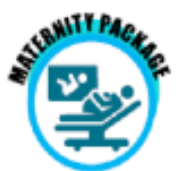

Maternal Care

Normal \& ceasarian delivery

Antenatal \& postnatal

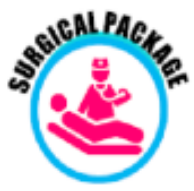

Surgical Package
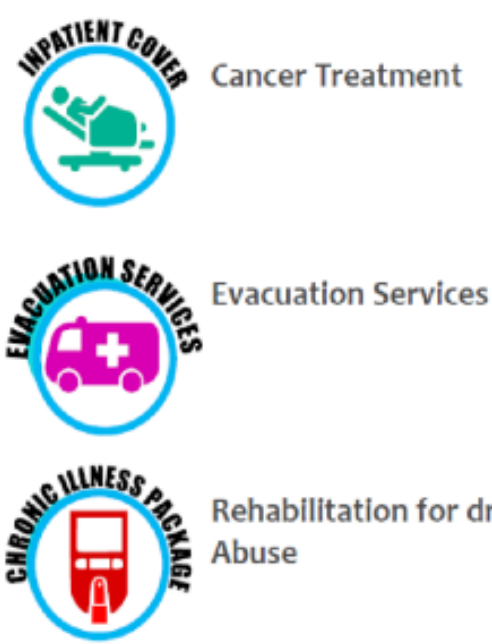

Rehabilitation for drug \& Substance

Abuse

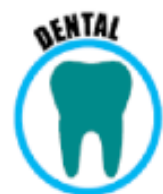

For Managed Schemes

Dental

Optical levels of unmet need for FP and its co-location with more marginalised and poorer populations, focusing on making markets work for these segments is suggested. Figure 2 exemplifies this as counties with lower MCPR (those at the bottom of the S-curve) are those with higher poverty rates, lower literacy and economic empowerment and tend to be concentrated at the 'outer edges' of the country, in the arid and semi-arid lands of Kenya.

\section{PACKAGE: WHAT TO PURCHASE}

In the absence of a health financing strategy, benefit objectives and priority setting have not always been explicit or transparent. The $\mathrm{MoH}$ defined benefit package of services, the Kenya Essential Package of Health (KEPH), considered more oriented to the public sector, has not guided the development of NHIF packages (Tama et al, 2017). In lieu of this, successive NHIF packages have been added (Figure 3 ), without broad consultation or consideration of equity (Munge et al, 2017). These have increasingly catered to NCDs given the burden of lifestyle diseases among higher socio-economic groups, including those in formal employment, the primary members of the NHIF.

More recently (2018), a health benefits advisory panel was established to define a UHC benefits package. It is unclear what guiding principles were used by the panel, the majority of whom were male and medical. Arrangements such as these do not suggest explicit protection and careful linking of benefits to needs of target populations, such as poor women and adolescent girls. This may be due to the MoH's explicit attention to women in relation to their reproductive roles, as mothers, through the provision of a free maternity scheme, entitled Linda Mama. A secondary school student package has also recently been introduced. This does not include contraception but does allow students to be linked to Linda Mama for free maternity care. Neither of these schemes adequately address FP services and prevention of pregnancy.

FP is included in the NHIF national scheme and Linda Mama; however, this is not well understood by providers or insurance members (or even by NHIF staff). Permanent methods, tubal ligation and vasectomy, are included as in-patient services paid on a fixed fee-for-service basis. All other methods, including long-acting reversible contraception (LARC), are included in the out-patient scheme, paid through capitation. Within the Linda Mama scheme, post-partum FP is included as part of post-natal care (PNC) but the reimbursement rate for each PNC visit is flat and does not reflect the cost of offering this service. A Kenya case study from the Africa Health Markets for Equity (AHME) program noted that, in many instances, NHIF branch staff and accredited providers were unclear on the inclusion of $\mathrm{FP}$, in terms of specific services and methods, as part of the out-patient scheme (Appleford and Owino, 2017). This is not without reason, as NHIF out-patient guidance is vague (Figure 4). Guidance indicates the provision of natural, hormonal, and permanent FP but does not specify which methods, except for IUCD. This lack of clarity has implications for adoption of specific methods, method switching and continuation.

\section{PROVIDER: FROM WHOM TO PURCHASE}

Kenya has a mixed health system, comprised of public and private providers, that is largely pro-PHC (Figure 5). This is comprised of an estimated 8,400 health facilities distributed 
Family planning

- Consultation with a clinician

- Health education on natural and artificial family planning methods

- Assessment for appropriateness of particular methods (Natural, Hormonal, and IUDs)

- Initiation/administration of a particular FP method

- Change of a family planning method

Radiology Services - Basic x-rays are covered under the general outpatient and inpatient care while MRI and CT scans are available in select facilities under a referral system with a pre-authorization from NHIF

Inpatient Services - Including accommodation/bed charges, nursing care, consultation, prescribed drugs/medication, laboratory services, surgery, physiotherapy, specialist consultation and treatment

Maternity Services - including prenatal care, child delivery - normal and caesarean section, postnatal care, Manual Vacuum Aspiration (MVA) and family planning services

Kidney Care package - including Renal Dialysis through inpatient or outpatient for a maximum of two sessions in a week, Kidney transplants at approved facilities

Drug and Rehabilitation services - at accredited rehabilitation centers at maximum of one treatment session in a year.
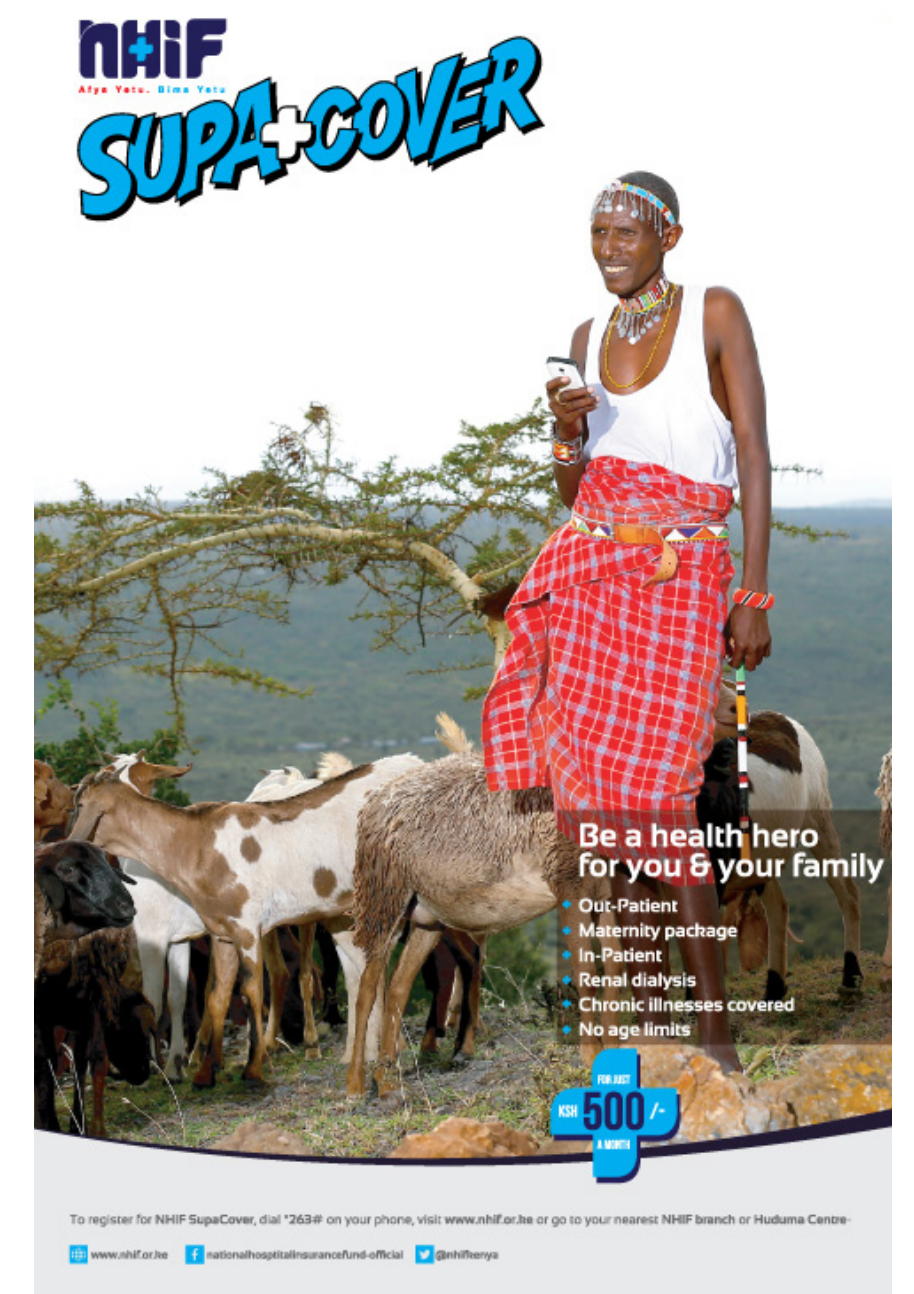

paid for through ear-marked sources of financing (via donors and the national government), given that most counties have not purchased FP commodities through their own revenue sources. Public facilities are given priority for commodities, however private facilities may also access these, when available, if they are registered with a Master Facility List number and provide monthly service reports using $\mathrm{MoH}$ registers.

- National and county governments (47 in total) purchase healthcare services from public health facilities, which they own. This includes three tertiary care hospitals (national level) and primary and secondary public health facilities (county level). Services are paid for through line-item budgets, the majority of which goes to personal emoluments leaving little available for programs, such as RH/FP.

- The NHIF purchases services from public and private health facilities on behalf of registered NHIF members. These are defined in various service packages, ranging from the most basic (SupaCover) to more compre- 


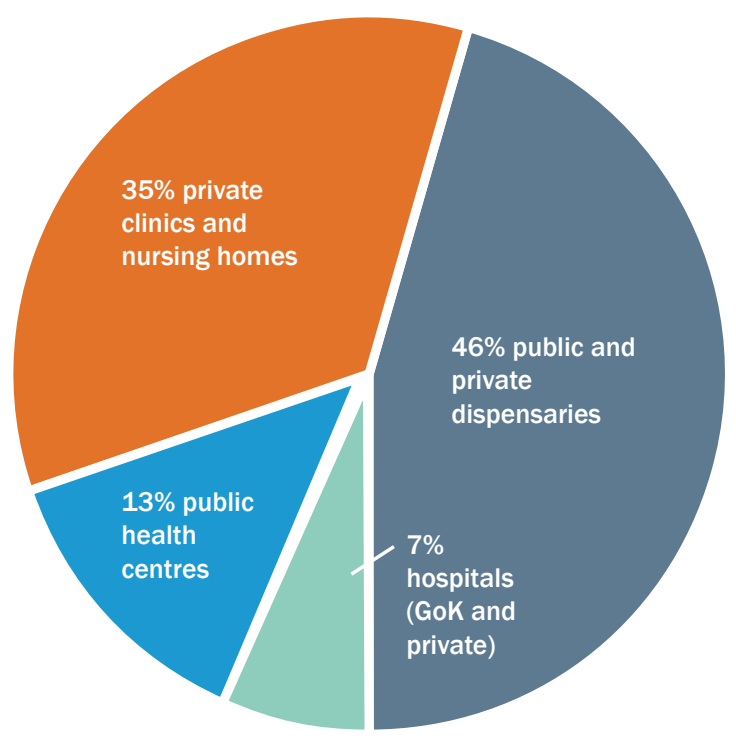

hensive packages (e.g. civil servants and corporate schemes). The in-patient package includes surgical FP procedures while the out-patient package includes long- and short-acting methods of FP.

- The NHIF purchases services from public and private health facilities under Linda Mama as part of its managed schemes and sponsored programs. The maternity service scheme was formerly managed as a fee exempt service package by the $\mathrm{MoH}$, whereby public health facilities were reimbursed for foregone user fees at agreed reimbursement rates. The Linda Mama scheme has extended this to private facilities and, in theory, includes post-partum FP (counseling, commodity, service and any after care requirements).

- $\quad$ Results-based purchasing, which entails financing from donors (e.g. World Bank and the Global Financing Facility), channeled through the Ministry of Finance to purchase services at county level. While purchasing mainly targets public providers, counties may also purchase services from the private sector should they wish to do so. FP is one of six results-based performance indicators.

- Bespoke county UHC schemes intended to purchase $\mathrm{PHC}$ services for indigent populations. Often this is in the form of removal of user fees at public hospitals (given that primary levels are, in principle, free). These schemes have been initiated at the request of county governors and are often politically motivated.

The range of purchasing points necessitate coherence between national and county level. In some instances, this is demonstrated; for example, results-based purchasing is ini- tiated at national level and executed at county level and is coordinated through annual workplans implemented mainly through the public sector. In other instances, this is not demonstrated. For example, commodity procurement, initiated and financed by counties, is used to procure commodities from KEMSA. However, counties have not prioritized - or resourced - FP to the level previously done by the national $\mathrm{MoH}$ before devolution. As noted, 'the Kenya government provided $40 \%$ of FP commodities in 2013 , dropping to $2.9 \%$ in 2015 due to changes related to the decentralization of the health budget. Based on lessons learnt, there is now near consensus that, procurement of FP commodities should not have been devolved' (GoK/MoH, 2017).

The mix of public and private providers also necessitate an integrated or whole sector approach to health service delivery. However, county departments of health, the stewards of PHC, may view the private sector more as 'foe' than 'friend'. This is reflective of an emergent political economy in Kenya where the private sector is being presented in government and the media as 'profit driven'. This viewpoint appears to emanate from capture of the NHIF market by the private sector, when the public sector was in a particularly weakened state during sequential industrial action by doctors and nurses in 2017. This portrayal of the private sector has been writ large and may extend to health facilities operating in Kenya's rural counties. In these contexts, some private providers, particularly smaller, female run clinics and nursing homes, report being discriminated against by the NHIF, through such tactics as delayed or frustrated NHIF and Linda Mama accreditation and processing of reimbursement claims (Appleford, forthcoming). Active participation of the private sector in purchasing arrangements, such as the NHIF and Linda Mama, has implications for client choice, particularly where physical access and FP availability and quality in the public sector may be constrained.

\section{PAYMENT: HOW TO PURCHASE}

While Kenya's health sector has articulated long-term policies, these do not explicitly address how to purchase. Within the Kenya Health Policy (2014-2030), and a five-year strategic plan, the Kenya Health Sector Strategic Plan, this is implied more than stated, through emphasis on health systems efficiency and quality (Tama et al, 2017). The $\mathrm{MoH}$ defined benefit package, the Kenya Essential Package for Health (KEPH), is also silent on strategic purchasing.

In practice, purchasing mechanisms (outlined under provider) tend to operate in isolation with implications for efficiency and quality. While greater decision making over domestic resources was intended to reap a 'devolution dividend', this has not been optimized due to weak coor- 
dination between national and county levels $(\mathrm{GoK} / \mathrm{MoH}$, 2016). This is most clearly exemplified by the commodity disconnect between counties and KEMSA. Within county health systems, devolution has also been accompanied by a perceived trend toward reduced autonomy among public health facilities (Barasa et al, 2017). This trend, termed 'recentralization within decentralization' (Barasa et al, 2017) has in effect countered the objectives of devolution through, inter alia, reduced responsiveness and local accountability in many of Kenya's counties. In the case of FP, this has created a situation of erratic FP commodity availability and depressed quality and choice within the public sector.

\section{Choice of payment method may also depress the pro-} vision of FP under the NHIF. Within the NHIF outpatient scheme, capitation was selected as the preferred means of provider payment 'to induce positive incentives in the health delivery system' (GoK, 2012). However, this may not be the case for FP. While capitation is a cost containment strategy, some FP services, such as LARC, are less likely to be offered by providers as there is no additional reimbursement for such services. Instead, capitation is likely to induce providers to offer cheaper, easier to administer methods, over LARC methods that require more time, skills and consumables. This, in effect, may reduce contraceptive choice and result in continued OOP expenditure for women covered under the NHIF.

\section{A similar situation also exists for post-partum FP under} the Linda Mama scheme. A case study from Bungoma county found that none of the providers interviewed as part of the study were aware that post-partum FP was included as part of the PNC package as the reimbursement rate for each PNC visit is flat and low (KES 250 or US $\$ 2.50$ per visit) and does not come with an additional reimbursement or guarantee of free commodities (Appleford and Mbuthia, 2018). The effective inclusion of modern post-partum FP in Linda Mama would allow Kenya a viable strategy for improving its uptake, which is estimated at only $16 \%$ at six months, despite an estimated $64 \%$ of women delivering in health facilities (Avenir Health, 2017). This is a missed opportunity for post-partum women under Linda Mama, many of whom are rural and poor.

\section{CONCLUSION}

FP uptake in Kenya has grown significantly but county disparities and population inequities remain. Devolution, while intended to address health system performance and accountability, has contributed to a situation of FP commodity insecurity, with implications for equity and access. While more can be done within the envelope of available health financing mechanisms, there is need for sustained and additional resources to meet current demands for FP and address unmet and latent need across counties represented on Kenya's S-curve.

Transition away from donor to domestic financing is not clearly articulated or well stewarded within the Kenya context. This is compounded by an array of sources of financing and purchasing points. The capacity of the national and county level to steward the public and private sectors and create the conditions for active purchasing from both is required. This includes autonomous decision making over financial resources within public health facilities as well as the inclusion and active participation of private providers in UHC schemes. Within these schemes, how FP services are compensated should balance incentives for efficiency with incentives for appropriate provision using the rights-based approach to user-centric care so that risks of sub-optimal outcomes are mitigated. The five P framework serves to highlight disconnects but also opportunities that could guide greater alignment across purchasing mechanisms.

\section{REFERENCES}

Appleford, G and B Mbuthia, 2018. Implementing Linda Mama in Bungoma County: Lessons on the path to universal health care. Maternal and Newborn Health Initiative (MANI). Options Consulting Ltd, Nairobi, Kenya.

Appleford, G. and E. Owino, 2017, National Hospital Insurance Fund tariffs - what are the effects on Amua franchisee businesses? Marie Stopes International, London, UK.

Avenir Health, 2017. Opportunities for Family Planning Programming in the Post-Partum Period in Kenya. Avenir Health, Connecticut, USA.

Barasa EW, Manyara AM, Molyneux S, Tsofa B, 2017. Recentralization within decentralization: County hospital autonomy under devolution in Kenya. PLoS One [Internet]. Public Library of Science; 2017; 12: e0182440. Available from: https://doi.org/10.1371/journal.pone.0182440

FP2020 Kenya. http://www.familyplanning2020.org/kenya [Retrieved 9/12/2018].

Government of Kenya, Ministry of Health, 2012. Kenya Draft Health Financing Strategy, Report of an External Review. Commissioned by the Ministry of Medical Services, Nairobi, Kenya.

Government of Kenya, 2012. Sessional Paper No. 7 on the Policy on Universal Health Care Coverage in Kenya. Nairobi, Kenya: Ministry of Medical Services. 
Government of Kenya, Kenya National Bureau of Statistics (GoK/KNBS), 2014. Kenya Demographic Health Survey (KDHS). http://dhsprogram.com/publications/publication-FR308-DHS-Final-Reports.cfm

Government of Kenya, Ministry of Health, 2014. Kenya Service Availability and Readiness Assessment Mapping (SARAM). Ministry of Health, Nairobi, Kenya.

Government of Kenya, Ministry of Health, 2016. Kenya Reproductive, Maternal, Newborn, Child and Adolescent Health (RMNCAH) Investment Framework, Ministry of Health, Nairobi, Kenya.

Government of Kenya, Ministry of Health, 2017. Kenya FP Costed Implementation Plan (2017-2020). Ministry of Health, Nairobi, Kenya.

IQVIA, 2018. Current Family Planning Market Conditions in Kenya, baseline 2018 interim findings. Prepared for Palladium.

Korachais, C., E. Macouillard, and B. Meessen. 2016. “How user fees influence contraception in low and middle income countries: A systematic review," Studies in Family Planning 47(4): 341-356.

Munge, K, Mulupi, S, Barasa, E.W. and J. Chuma, 2017. A Critical Analysis of Purchasing Arrangements in Kenya: The Case of the National Hospital Insurance Fund. http://ijhpm. com Int J Health Policy Manag 2017, 6(x), 1-11.

PMA2020, 2018 (May). Family Planning Brief, Round 6 (Nov-Dec 2017). Nairobi, Kenya.

RESYST, 2014. What is Strategic Purchasing for Health? Topic Overview 4, Financing research theme; Resilient and Responsive Health Systems, London School of Hygiene and Tropical Medicine, London, UK [Retrieved 3/11/2018].

Radovich, E, Dennis ML, Cavallaro, F, Lynch, CA, Wong, K, Lyons-Amos, M and L Benova (2017). Examining out-ofpocket payments for contraceptives among users of public and private providers in Kenya. LSHTM.

Sidze, EM, Pradhan, J, Beekink, E, Maina, TM and BW Maina (2013). Reproductive health financing in Kenya: an analysis of national commitments, donor assistance, and the resources tracking process, Reproductive Health Matters, 21:42, 139-150, DOI: 10.1016/S09688080(13)42738-6.
Tama E, Molyneux S, Waweru E, Tsofa B, Chuma J, Barasa E. Examining the implementation of the free maternity services policy in Kenya: a mixed methods process evaluation. Int J Health Policy Manag. 2017;6(x):x-x. doi:10.15171/ ijhpm.2017.135.

Witter, S, Govender, V, Ravindran, TKS and R Yates, 2017. Minding the gaps: health financing, universal health coverage and gender. Health Policy and Planning, 32, 2017, v4-v12 doi: 10.1093/heapol/czx063

World Bank, 2013. The World Bank Service Delivery Indicators Program. http://siteresources.worldbank.org/ AFRICAEXT/Resources/SDI-Report-Kenya.pdf [accessed 6/11/2018].

\section{ACKNOWLEDGMENTS}

We thank the David and Lucille Packard Foundation for their generous support which made this work possible. We also thank Leah Jarvis for her review and insightful comments.

Suggested citation: Gabrielle Appleford and Saumya Ramarao, 2019. Health financing and family planning in the context of Universal Health Care: connecting the discourse in Kenya. Population Council, New York. 